\title{
Recommendations for the Prevention, Detection, Treatment and Management of Prescription Opioid Analgesic Dependence: Outcomes From the Opioid Analgesic Dependence Education Nexus (OPEN) Meeting
}

\author{
Mark Kraus ${ }^{1,2}$ • Nicholas Lintzeris ${ }^{3,6}$ - Christoph Maier ${ }^{4}$. \\ Seddon Savage ${ }^{5,7}$
}

Published online: 3 December 2015

(C) Springer Science+Business Media New York 2015

\begin{abstract}
The global consumption of opioids continues to rise, which has led to an increasing rate of diversion, misuse, addiction, and deaths related to prescription opioids. This has been particularly well documented in the USA; however, opioid analgesic dependence (OAD) is an increasing concern in Europe. More guidance is required for European healthcare professionals in the prevention, detection, treatment and management of OAD. The first Opioid Analgesic Dependence Education Nexus (OPEN) Mentor Meeting was held in Berlin in September 2014 to address this. An international Expert Panel, combining expertise in OAD from Australia, USA and Europe, invited 16 European experts in the pain and addiction fields to develop a best-practice approach to OAD that European practitioners can adopt. The outcomes from this meeting are presented here and included are a set of shared strategies that may be universally adopted by all healthcare professionals working with patients who use opioids.
\end{abstract}

Keywords Opioids · Analgesics · Dependence $\cdot$ Prescription $\cdot$ Shared strategies

Mark Kraus

mlk@wsmgct.com

1 Yale University School of Medicine, New Haven, CT, USA

2 Franklin Medical Group, Waterbury, CT, USA

3 South Eastern Sydney Local Health District, Sydney, Australia

4 Bergmannsheil Hospital, Ruhr-University, Bochum, Germany

5 Geisel School of Medicine, Dartmouth College, Hanover, NH, USA

6 Central Clinical School, Sydney Medical School, University of Sydney, Sydney, Australia

7 Silver Hill Hospital, New Canaan, CT, USA 
Opioid analgesics are prescribed for moderate-to-severe pain, with numerous opioids classified by the World Health Organization as essential medicines in the treatment of pain; however, opioid dependence can develop in vulnerable persons with ongoing administration of opioid medications and, as a result, opioid analgesic dependence (OAD) has become a global concern. In addition to those receiving legal opioid prescriptions for pain, other populations develop OAD through independent misuse of opioids. OAD has social, psychological and physical consequences for the patient; risks to others through medication misuse, diversion and accidental exposure; and also places a financial burden on healthcare systems.

The incidence of OAD is particularly pronounced in the USA and Australia. Opioid analgesics were involved in $43 \%$ of all drug overdose deaths in the USA in 2010 (Jones et al. 2013) and were responsible for more than twice the number of deaths from heroin and cocaine combined (Giraudon et al. 2013). In Australia, non-medical use of pharmaceutical opioids doubled between 2007 and 2010 (Roxburgh et al. 2013); however, opioid analgesic consumption is rapidly increasing outside of these countries (International Narcotics Control Board 2014). Many European countries consume greater than $100 \mathrm{mg} /$ capita morphine equivalence (International Narcotics Control Board 2014). Opioid analgesics are regarded by international health experts as the gold standard for relieving moderate-to-severe acute pain and some persistent pain (Joranson et al. 2010). However, there is a need to balance access to prescription opioids with prevention of dependence and other harms. Yet, in the USA, prescription opioid overdoses and treatment admission for opioid dependence have increased in line with increased access to opioid analgesics (Paulozzi et al. 2011). An association between higher dosing schedules in pain treatment and opioid overdoses has been demonstrated (Bohnert et al. 2011), and overdoses may occur as a result of misuse of diverted opioids. A recent review of opioid prescription data across several European countries revealed that there are an estimated 22.8 million patients using prescription opioid analgesics, with an estimated 455,000 likely to be dependent (Alho 2013). As access to opioid analgesics continues to increase across Europe (International Narcotics Control Board 2014) (Fig. 1), there is a growing need to provide education to both doctors and patients to prevent Europe mirroring the trends in OAD seen in the USA and Australia.

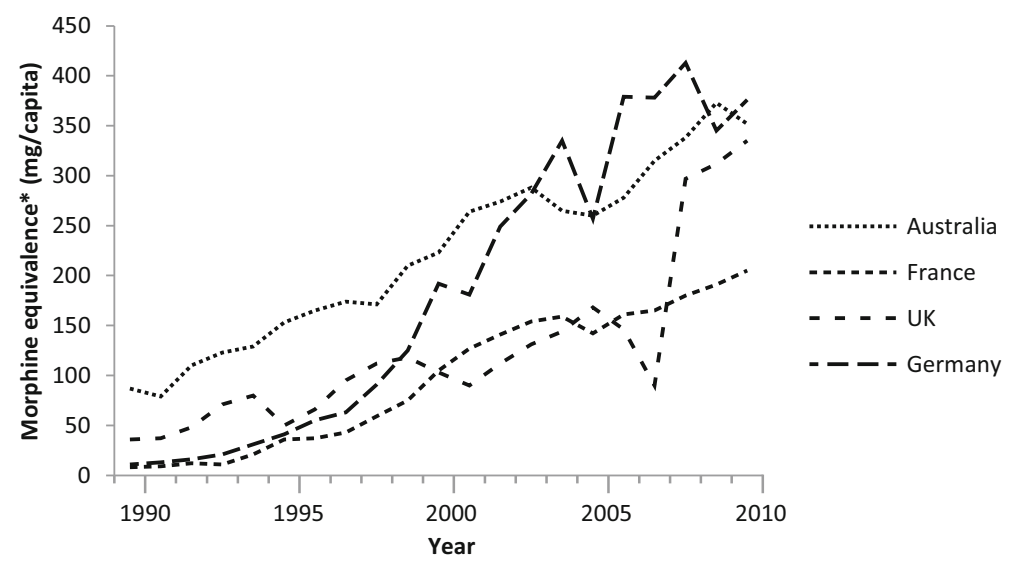

Fig. 1 Opioid consumption in Europe is increasing. This graph illustrates the increase in opioid consumption in European countries, following a similar trend in increases that has been seen in Australia. Data from the International Narcotics Control Board. United Nations population data. Available at: https://ppsg.medicine. wisc.edu/chart [Last accessed 6 October 2014]. *Morphine equivalence (ME) allows for equianalgesic comparisons between countries of the aggregate consumption of six principal opioids (fentanyl, hydromorphone, methadone, morphine, oxycodone, and pethidine) 
Treatment of $\mathrm{OAD}$ is complicated by the frequent persistence of comorbid pain, which can yield a variety of sub-populations that respond best to different treatment strategies. Interestingly, some pain patients receive dose escalations without concomitant relief from pain and actually experience greater pain-relief from opioid withdrawal (Krumova et al. 2013). Currently, more guidance is required for healthcare professionals in Europe on the prevention, detection, treatment and management of prescription OAD. The Opioid Analgesic Dependence Education Nexus (OPEN) was created to meet this need by providing education to practitioners and also to raise awareness of OAD in Europe. As American and Australian experts in the fields of pain and addiction, with extensive experience of $\mathrm{OAD}$, combined with the support of a leading European pain expert with the knowledge of the European OAD landscape, we convened in order to form a consensus for best practice in the prevention, detection, management and treatment of $\mathrm{OAD}$ and to create a comprehensive educational toolkit that could be shared amongst practitioners across Europe to provide guidance to healthcare professionals.

\section{Methods}

\section{The Opioid Analgesic Dependence Education Nexus (OPEN) Mentor Meeting 2014}

The Opioid Analgesic Dependence Education Nexus (OPEN) Mentor Meeting 2014 was held in Berlin on 18-19 September 2014. The meeting content was created by the international Expert Panel: Associate Professor Nicholas Lintzeris, Director of Drug and Alcohol Services, Australia; Professor Seddon Savage, Adjunct Associate Professor of Anaesthesiology, USA; Professor Mark Kraus, General Internist, USA; and Professor Christoph Maier, Endowed Chair in Pain Management, Germany. Experts from across Europe were selected to attend the meeting based on their clinical and scientific expertise in OAD and their reputation as a key opinion leader at an international or national level; a strong publication record was also desirable. In total, 16 European experts attended the meeting: 7 from the UK, 3 from Germany and 6 from France. There were 2 pain specialists, 13 addiction specialists and 1 pain and addiction specialist.

\section{OPEN Mentor Survey}

The 16 European experts were invited to complete a survey during the meeting that was designed by the Expert Panel to assess the European experts' views of OAD in Europe; current unmet needs in the field; and recommended strategies for the prevention, detection, treatment and management of OAD. The survey was completed independently and anonymously, and results were collected from 13 experts.

\section{Shared Strategies}

The Expert Panel convened for three meetings to develop a consensus and propose a set of shared strategies to be used as guidance for healthcare professionals in the prevention, treatment and management of OAD. At the OPEN meeting in Berlin, the 16 European experts were invited to indicate their support for the strategies through an anonymous and independent vote. The experts were asked the extent to which they agreed that the proposed strategies would provide useful guidance and be applicable to the prevention, detection, treatment and management of OAD in Europe. Answers were given on a 4-point Likert Scale from 'strongly agree' to 'strongly disagree'. 
The strategies were placed at stations and the experts invited to visit each station and contemplate and discuss each strategy before completing a voting slip. 15 of the European experts took part in this activity. The 15 experts voted on 8 of the 14 shared strategies; the remaining 6 strategies were voted on by $12-14$ of the experts. Logistical issues limited all experts from voting on all strategies.

\section{Results}

\section{The Scale of the Problem in Europe - the European Expert Survey}

We present here the results of a survey we developed in order to assess the OAD landscape in Europe, including the scale of the problem, treatment strategies and challenges. Of the 16 European experts invited to complete the survey, 13 submitted responses.

- $100 \%$ of the European experts surveyed believe that OAD is a priority problem in Europe that needs special attention.

- $100 \%$ of the European experts surveyed believe that OAD is increasing in the country in which they practise (UK, France and Germany).

- $100 \%$ of the European experts surveyed acknowledge the importance of diagnosing and treating $\mathrm{OAD}$.

- $\quad 69 \%$ believe this to be very important.

- $\quad 31 \%$ believe this to be important.

- $85 \%$ of the European experts surveyed marked education of doctors and/or patients as a key strategy for the prevention of OAD.

- The European experts most frequently reported codeine and tramadol as the opioids they believe their patients are most commonly dependent upon.

- $100 \%$ of the European experts surveyed acknowledged the importance of multidisciplinary care, individualised treatment, involving patients in treatment decisions and designing treatment that does not impede the patient's ability to participate fully in their career or educational activities (Table 1).

Table 1 European experts in pain and addiction endorse the following treatment approaches for OAD. The experts ranked each approach on a 4-point Likert scale of $1-4$, where 1 is 'Not important' and 4 is 'Very important'

\begin{tabular}{|c|c|c|c|c|}
\hline & Treatment approaches & Mean score & Level of importance & No. votes \\
\hline 1 & A multidisciplinary approach to care & 3.69 & Very important & 13 \\
\hline 2 & Individualised treatment & 3.85 & Very important & 13 \\
\hline 3 & Involved patients in treatment goals and decisions & 3.92 & Very important & 13 \\
\hline 4 & $\begin{array}{l}\text { Design treatment that does not impede the patient's ability to } \\
\text { participate fully in their career or educational activities }\end{array}$ & 3.77 & Very important & 13 \\
\hline 5 & $\begin{array}{l}\text { Prescribe treatments that minimise the risk of misuse } \\
\text { and diversion }\end{array}$ & 3.69 & Very important & 13 \\
\hline
\end{tabular}


Table 2 European experts in pain and addiction endorsed 14 shared strategies developed by an Expert Panel of international experts that can be universally adopted for the prevention, detection, treatment and management of OAD. Mentors ranked each strategy on a 4-point Likert Scale of 1-4 where 1 is 'Strongly agree' and 4 is 'Strongly disagree'

\begin{tabular}{ll}
\hline & Shared Strategy \\
\hline $1 \quad$ OAD may result from a combination of \\
factors that should be taken into \\
account during all stages of patient \\
contact, including at the time of \\
prescribing pain medication, during \\
the detection of OAD and \\
throughout the treatment of OAD. \\
2 A comprehensive clinical assessment
\end{tabular}

2 A comprehensive clinical assessment should be performed on all patients who may be considered to be dependent on opioid analgesics. This should include:

- a comprehensive assessment of the patient's substance use history

- a comprehensive assessment of the patient's mental health

- assessment of other health and social issues

- a physical examination (current opioid intoxication/withdrawal).

3 OAD patients who are no longer in pain and recreational opioid analgesic users should have treatment that focuses on ad dressing their dependence.

4 For OAD patients with co-existing pain, treatment must address both chronic conditions.

5 Treatment should be holistic and manage pain (if applicable), opioid dependence, social situations and mental health, in addition to taking into account complexities such as age or comorbidities.

6 Prescribing should not be undertaken in isolation. Healthcare professionals should foster multidisciplinary collaboration to achieve the best possible outcomes for their patients.

7 Whether detoxification or maintenance treatment is offered, psychosocial services should be made available to all patients; although, those who do not take up the offer should not be denied effective pharmacological treatment.

$\begin{array}{lllllll}1 & 2 & 3 & 4 & \text { Mean } & \begin{array}{l}\text { Mean } \\ \text { level of } \\ \text { agreement }\end{array} & \begin{array}{l}\text { No. } \\ \text { of } \\ \text { vagree }\end{array}\end{array}$

$\begin{array}{lllllll}60.0 \% & 26.7 \% & 0.0 \% & 13.3 \% & 1.67 & \text { Agree } & 15\end{array}$

15 \\ 5}

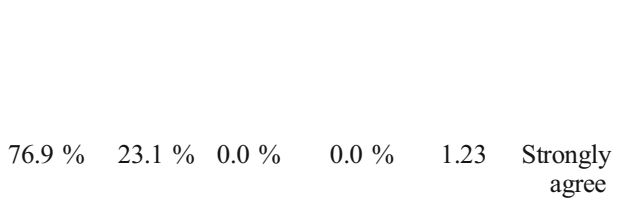

$\begin{array}{rllllll}76.9 \% & 23.1 \% & 0.0 \% & 0.0 \% & 1.23 & \begin{array}{r}\text { Strongly } \\ \text { agree }\end{array}\end{array}$

aree

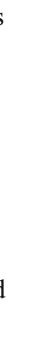

$\begin{array}{llllllll}69.2 \% & 30.8 \% & 0.0 \% & 0.0 \% & 1.31 & \begin{array}{c}\text { Strongly } \\ \text { agree }\end{array} & 13\end{array}$

$\begin{array}{llllllll}86.7 \% & 13.3 \% & 0.0 \% & 0.0 \% & 1.33 & \begin{array}{c}\text { Strongly } \\ \text { agree }\end{array} & 15 \\ 66.6 \% & 33.3 \% & 0.0 \% & 0.0 \% & 1.33 & \begin{array}{c}\text { Strongly } \\ \text { agree }\end{array} & 15\end{array}$

$\begin{array}{llllllll}66.6 \% & 33.3 \% & 0.0 \% & 0.0 \% & 1.33 & \begin{array}{c}\text { Strongly } \\ \text { agree }\end{array} & 15\end{array}$

$\begin{array}{cccccccc}64.3 \% & 35.7 \% & 0.0 \% & 0.0 \% & 1.36 & \begin{array}{c}\text { Strongly } \\ \text { agree }\end{array} & 14\end{array}$

8 When initiating maintenance treatment, do not assume that the analgesic being prescribed is what is being taken - patients may be using more or less than the amount prescribed or

$\begin{array}{lllllll}61.5 \% & 38.5 \% & 0.0 \% & 0.0 \% & 1.38 & \begin{array}{c}\text { Strongly } \\ \text { agree }\end{array} & 13\end{array}$


Table 2 (continued)

\begin{tabular}{|c|c|c|c|c|c|c|c|c|}
\hline & Shared Strategy & $\begin{array}{l}1 \\
\text { Strongly } \\
\text { agree }\end{array}$ & $\begin{array}{l}2 \\
\text { Agree }\end{array}$ & $\begin{array}{l}3 \\
\text { Disagree }\end{array}$ & $\begin{array}{l}4 \\
\text { Strongly } \\
\text { disagree }\end{array}$ & $\begin{array}{l}\text { Mean } \\
\text { score }\end{array}$ & $\begin{array}{l}\text { Mean } \\
\text { level of } \\
\text { agreement }\end{array}$ & $\begin{array}{l}\text { No. } \\
\text { of } \\
\text { votes }\end{array}$ \\
\hline & $\begin{array}{l}\text { administering their medication by } \\
\text { alternative methods. }\end{array}$ & & & & & & & \\
\hline 9 & $\begin{array}{l}\text { When initiating maintenance treatment, } \\
\text { primary healthcare professionals } \\
\text { should consider specialist advice or } \\
\text { referral in the following } \\
\text { circumstances: } \\
\text { - Patients who have an unclear level } \\
\text { of opioid tolerance } \\
\text { - Patients who have high-risk polydrug } \\
\text { use } \\
\text { - Patients who use other medications } \\
\text { that may affect the metabolism of the } \\
\text { maintenance treatment } \\
\text { - Patients who have concomitant } \\
\text { physical conditions } \\
\text { - Patients who have severe concomitant } \\
\text { psychiatric conditions } \\
\text { - Patients who seek higher and more } \\
\text { rapid dose increases } \\
\text { - Patients who have difficulty } \\
\text { stabilising on a dose due to } \\
\text { continued substance use, side } \\
\text { effects or other complications. }\end{array}$ & $46.7 \%$ & $53.3 \%$ & $0.0 \%$ & $0.0 \%$ & 1.53 & Agree & 15 \\
\hline 10 & $\begin{array}{l}\text { Patient care should be mindful of the } \\
\text { stigmatisation that can be felt by } \\
\text { patients dependent on opioid } \\
\text { analgesics. }\end{array}$ & $60.0 \%$ & $26.7 \%$ & $13.3 \%$ & $0.0 \%$ & 1.53 & Agree & 15 \\
\hline 11 & $\begin{array}{l}\text { The impact that treatment may have on } \\
\text { the patient, for example on their } \\
\text { work and family commitments or the } \\
\text { management of their ongoing pain, } \\
\text { should be considered and the } \\
\text { treatment should be tailored } \\
\text { accordingly. }\end{array}$ & $50 \%$ & $50 \%$ & $0.0 \%$ & $0.0 \%$ & 1.5 & $\begin{array}{l}\text { Strongly } \\
\text { agree }\end{array}$ & 12 \\
\hline 12 & $\begin{array}{l}\text { The treatment and management of } \\
\text { OAD patients should be } \\
\text { individualised based on ongoing } \\
\text { patient monitoring and assessment. }\end{array}$ & $58.3 \%$ & $41.7 \%$ & $0.0 \%$ & $0.0 \%$ & 1.42 & $\begin{array}{l}\text { Strongly } \\
\text { agree }\end{array}$ & 12 \\
\hline 13 & $\begin{array}{l}\text { Patient reviews should occur frequently } \\
\text { (eg every week) early in treatment, } \\
\text { during periods of instability or } \\
\text { during withdrawal attempts. Stable } \\
\text { patients should be reviewed at least } \\
\text { once a month or when there is a } \\
\text { change in the patient's } \\
\text { circumstances. }\end{array}$ & $40.0 \%$ & $53.3 \%$ & $6.7 \%$ & $0.0 \%$ & 1.47 & $\begin{array}{l}\text { Strongly } \\
\text { agree }\end{array}$ & 15 \\
\hline 14 & $\begin{array}{l}\text { Measures should be taken to minimise } \\
\text { misuse and diversion of maintenance } \\
\text { medications. }\end{array}$ & $60.0 \%$ & $40.0 \%$ & $0.0 \%$ & $0.0 \%$ & 1.40 & $\begin{array}{l}\text { Strongly } \\
\text { agree }\end{array}$ & 15 \\
\hline
\end{tabular}

Regarding medication-assisted treatment for OAD, of the 11 European experts who responded, 2 stated a preference to structure their patient's treatment with their current opioid 
as a first-line treatment strategy. If this is not possible, one expert recommended buprenorphine/naloxone and the other recommended either methadone or buprenorphine depending on the patient's need. The remaining 9 respondents listed buprenorphine or buprenorphine/naloxone as their preferred treatment choice owing to the safety profile, low stigma, efficacy and availability of the abuse deterrent formulation.

\section{Shared Strategies for the Prevention, Detection, Treatment and Management of OAD - the Expert Consensus}

We developed 14 shared strategies, based on our international experience of OAD and specialist experience in the pain and addiction fields, that we believe can be universally adopted by practitioners for guidance in the prevention, detection, treatment and management of OAD. The European experts reviewed and indicated their support for the shared strategies by ranking their agreement with the strategies on a 4-point Likert Scale from 'strongly agree' to 'strongly disagree'. The shared strategies gained unanimous support; following analysis of the participants' scoring, participants strongly agreed with 11 of the strategies and agreed with the remaining 3 strategies (Table 2).

\section{Conclusions}

With a lack of centralised data collection and uncertainty regarding the rates of OAD, it is difficult to estimate the scale of the problem in Europe arising from opioid analgesic dependence. We created a survey and consensus process among European experts in pain and addiction in order to assess the OAD landscape in Europe from a practitioner's perspective, including the scale of the problem, treatment strategies and challenges. Notably, all of the European experts surveyed believe that $\mathrm{OAD}$ is a priority problem in Europe that needs special attention and that OAD is increasing in the countries in which they practise (UK, France and Germany). These findings should alert healthcare professionals across Europe to the growing problem of OAD and we, the Expert Panel, together with the European experts agree that more education and guidance is required in this field; the findings also need to be shared between primary care physicians, pain specialists and addiction specialists to ensure that awareness, support and collaboration between multiple service agencies can be focused on addressing this emerging problem.

Together with the European experts, we have agreed a series of shared strategies that we believe can be universally adopted by practitioners for guidance in the prevention, detection, treatment and management of OAD. By recommending these strategies in this publication, we hope to provide a foundation for European guidance in OAD that can be shared among European practitioners. Of the 14 shared strategies proposed, the European experts strongly agreed with 11 of the strategies and agreed with the remaining 3 . The following strategies gained the most support:

- A comprehensive clinical assessment should be performed on all patients who may be considered to be dependent on opioid analgesics. This should include:

- a comprehensive assessment of the patient's substance use history

- a comprehensive assessment of the patient's mental health

- assessment of other health and social issues

- a physical examination (including evidence of current opioid intoxication/withdrawal). 
- OAD patients who are no longer in pain and recreational opioid analgesic users should have treatment that focuses on addressing their dependence.

- For OAD patients with co-existing pain, treatment must address both chronic conditions.

- Treatment should be holistic and manage pain (if applicable), opioid dependence, social situations and mental health, in addition to taking into account complexities such as age or comorbidities.

- Prescribing should not be undertaken in isolation. Healthcare professionals should foster multidisciplinary collaboration to achieve the best possible outcomes for their patients.

These strategies highlight the importance of multidisciplinary care and the utilisation of additional expertise rather than practising in isolation and emphasise the need to manage all aspects of a patient's wellbeing. A comprehensive clinical assessment is key and should evaluate the physical, psychological and social state of the patient. Should a patient be in intolerable ongoing pain, it is necessary to ensure that the patient continues to be treated for their pain alongside treatment for any dependence issues. In the course of this process, the European experts also emphasised the importance of multidisciplinary care, individualised treatment, involving patients in treatment decisions and designing treatments that do not impede the patient's ability to participate fully in their career or educational activities. The role of withdrawal from opioids in patients experiencing problems with their opioid analgesics was also debated. Whilst a trial of opioid withdrawal was considered to be warranted for many such patients, high rates of relapse to opioid use in dependent patients (Kakko et al. 2003) highlights the importance of individualised treatment plans and the need for flexibility in responding to patient outcomes. These recommendations and strategies echo those recently introduced for management of pain in the 2014 Australian National Guidelines for Medication-Assisted Treatment of Opioid Dependence (Gowing et al. 2014) and can be universally adopted by all healthcare professionals working with patients who use opioids. Further education on OAD for European practitioners is required, and this paper should form a basis for the development of more detailed guidelines that can be used across healthcare disciplines to help manage those patients who become dependent on or who are likely to become dependent on opioid analgesics in the European setting.

\section{Limitations}

Our experts and participants represent a limited number of developed countries: three European countries, the United States and Australia. The observations contained herein therefore may not be generalisable to less developed countries or ones with highly different healthcare or cultural structures. While there was high agreement on both observations related to OAD and strategic approaches to addressing the problem across the countries surveyed, the limited number of participants, with only pain and/or addiction medicine backgrounds, may not reflect more diverse views within the countries represented. Finally, not all participants weighed in on all questions or strategies, but because of widespread agreement among those who did respond, we perceive that non-responses more likely reflect logistics rather than bias. Nonetheless, we believe the process reflects a growing concern and suggests some reasonable approaches to addressing the challenge. 
The Role of the Funding Source The Opioid Analgesic Dependence Education Nexus (OPEN) Meeting 2014 was supported by RB Pharmaceuticals Ltd. Medical writing services for the manuscript were funded by RB Pharmaceuticals Ltd. The Expert Panel did not receive honoraria for preparing this manuscript.

Contributors The authors gratefully acknowledge financial support from RB Pharmaceuticals Ltd in support of the OPEN meeting and in support of professional editorial assistance for the production of this manuscript. The manuscript represents the work of the authors with editorial assistance from PCM Healthcare Ltd. RB Pharmaceuticals Ltd has not reviewed the manuscript nor had any other influence on its content. The authors have had full control of the final content and the decision to publish.

Conflict of Interest Professor Kraus declares receiving honoraria for speaking from RB Pharmaceuticals and BioDelivery Sciences; receiving honoraria for being an advisory board member for RB Pharmaceuticals and BioDelivery Sciences; and receiving honoraria for being a speaker and board member for the American Society of Addiction Medicine Coalition on Physician Education in Substance Abuse Disorder.

Professor Lintzeris declares receiving an educational grant for investigator-led research regarding Suboxone from RB Pharmaceuticals and receiving honoraria for delivering professional education from RB Pharmaceuticals.

Professor Maier declares board membership/consultancy for Pfizer Pharma GmbH (Berlin), Mundipharma GmbH (Limburg), Mundipharma Research Ltd (Cambridge/UK), Epionics Medical GmbH (Potsdam), AstraZeneca GmbH (Wedel), Astellas Pharma GmbH (München), Quintiles Ltd (Berkshire/UK) and, Reckitt Benckiser Holding GmbH \& Co. KG (Mannheim); payment for educational presentations from Pfizer Pharma GmbH (Berlin), MSD Sharp \& Dohme GmbH (Haar), Lilly GmbH (Bad Homburg), Grünenthal GmbH (Aachen), and Mundipharma GmbH (Limburg); payment for research support from Mundipharma GmbH (Limburg), Grünenthal GmbH (Aachen), and Astellas Pharma GmbH (München); and is a member of the IMI 'Europain' collaboration, which is supported by AstraZeneca Pfizer, Esteve, UCB-Pharma, Sanofi Aventis, Grünenthal, Eli Lilly, and Boehringer Ingelheim German Federal Ministry of Education and Research (BMBF): German Network on Neuropathic Pain.

Professor Savage declares that she has no conflict of interest. She did not receive financial support for her participation in the OPEN meeting or for contributions to this manuscript.

\section{References}

Alho, H. (2013). Prevalence of prescription opioid-dependency in Europe and risk factors for abuse. International Society of Addiction Medicine (ISAM).

Bohnert, A., Valenstein, M., Bair, M. J., Ganoczy, D., Mccarthy, J. F., Ilgen, M. A., \& Blow, F. C. (2011). Association between opioid prescribing patterns and opioid overdose-related deaths. Journal American Medical Association, 305(13), 1315-1321.

Giraudon, I., Lowitz, K., Dargan, P. I., Wood, D. M., \& Dart, R. C. (2013). Prescription opioid abuse in the UK. British Journal of Clinical Pharmacology, 76(5), 823-824. doi:10.1111/bcp.12133.

Gowing, L., Ali, R., Dunlop, A., Farrell, M., \& Lintzeris, N. (2014). April 2014 National Guidelines for Medication-Assisted Treatment of Opioid Dependence.

International Narcotics Control Board. (2014). United Nations population data. Retrieved from https://ppsg. medicine.wisc.edu/chart

Jones, C., Mack, K., \& Paulozzi, L. (2013). Pharmaceutical overdose deaths, United States, 2010. Journal American Medical Association, 309(7), 657-659. Retrieved from http://ajph.aphapublications.org/doi/pdf/ 10.2105/AJPH.91.2.316

Joranson, D. E., Ryan, K. M., \& Maurer, M. A. (2010). Opioid policy, availability, and access in developing and nonindustrialized countries. In S. Fishman \& J. Ballantyne (Eds.), Bonica's Management of Pain (4th ed.).

Kakko, J., Dybrandt Svanborg, K., Kreek, M. J., \& Heilig, M. (2003). 1-year retention and social function after buprenorphine-assisted relapse prevention treatment for heroin dependence in Sweden: a randomised, placebo-controlled trial. Lancet, 361, 662-668. doi:10.1016/S0140-6736(03)12600-1.

Krumova, E. K., Bennemann, P., Kindler, D., Schwarzer, A., Zenz, M., \& Maier, C. (2013). Low pain intensity after opioid withdrawal as a first step of a comprehensive pain rehabilitation program predicts long-term nonuse of opioids in chronic noncancer pain. Clinical Journal of Pain, 29(9), 760-769.

Paulozzi, L. J., Kilbourne, E. M., \& Desai, H. A. (2011). Prescription drug monitoring programs and death rates from drug overdose. Pain Medicine, 60(43), 1487-1492.

Roxburgh, A., Ritter, A., Slade, T., \& Burns, L. (2013). Trends in drug use and related harms in Australia, 2001 to 2013. Sydney: National Drug and Alcohol Research Centre, University of New South Wales. 